\title{
Telemonitoring of Patients with Implantable Cardiac Devices to Manage Heart Failure: An Evaluation of Tablet-PC-Based Nursing Intervention Program
}

\author{
Aya Umeda ${ }^{1}$, Tomoko Inoue ${ }^{1}$, Takuri Takahashi', Hidetoshi Wakamatsu ${ }^{3}$ \\ ${ }^{1}$ Department of Critical and Invasive-Palliative Care Nursing, Tokyo Medical and Dental University, Tokyo, Japan \\ ${ }^{2}$ National Institute of Infectious Diseases, Tokyo, Japan \\ ${ }^{3}$ Department of Life Sciences and Bio-Informatics, Tokyo Medical and Dental University, Tokyo, Japan \\ Email: a-umeda@umin.ac.jp
}

Received 30 January 2014; revised 9 March 2014; accepted 27 March 2014

Copyright (C) 2014 by authors and Scientific Research Publishing Inc.

This work is licensed under the Creative Commons Attribution International License (CC BY). http://creativecommons.org/licenses/by/4.0/

\section{Open Access}

\section{Abstract}

Background: With the rapid aging of society, the number of patients with heart failure has also increased. Implantable devices for heart failure have become standardized. Remote monitoring using cardiac devices has grown in popularity for medical efficiency and the early detection of abnormalities. Our first aim was to develop a tablet-PC-based nursing intervention program for patients requiring remote monitoring of implantable cardiac devices. The second purpose was to evaluate the efficacy of the program by using mixed-methods research. Methods: The study consisted of two phases. In phase 1, we designed a tablet-PC-based nursing intervention program, on the basis of a literature review and qualitative data collected via semi-structured interviews. In phase 2 , we conducted a randomized controlled trial that served as a preliminary investigation of the program. The outcome measures were readmission, unexpected visits to the clinic for heart problems, quality of life, self-care behavior, and self-efficacy. After the study, we interviewed each participant about his or her experiences with the program. Interviews were audio recorded, coded, and thematically analyzed. Results: The 33 patients with heart failure were randomized into two groups as follows: 17 patients in the telenursing group and 16 in the control group. During 6 months of follow-up, the readmission for heart failure occurred in $11 \%$ of the intervention group and $18 \%$ of the control group. There were no statistically significant differences between the groups at any outcome measures. Three themes were extracted via qualitative analysis: "getting a sense of safety," "triggering a health behavior change," and "feeling like a burden." Conclusion: No improvements in rates of rehospitalization or unexpected clinic visits were seen in the quantitative study. However, signs of behavior modification were seen in the qualitative study. This program has the possibility of improving patient outcomes. 


\section{Keywords}

\section{Heart Failure; Telemonitoring; Telenursing; Remote Monitoring; Implantable Cardiac Devices}

\section{Introduction}

Similar to that in Western countries, the number of heart failure patients has increased in Japan. Moreover, it is anticipated that this number will increase in the future [1]. If chronic heart failure is allowed to progress far enough, it becomes irreversible, resulting in repeated hospitalizations due to heart failure exacerbations. Repeat hospitalizations confer a major burden on patients, their families, and society, and limit patient roles and life expectancy, leading to distress [2].

Meanwhile, heart failure treatments continue to evolve. The use of implantable cardiac devices, such as implantable cardioverter defibrillators (ICDs) and cardiac resynchronization therapy defibrillators (CRT-D), has become standard. Although implantable cardiac devices are beneficial for improving patient prognosis, many patients with such devices still require urgent clinic visits or rehospitalization due to aggravated heart failure, arrhythmia, and unexpected device problems. To solve these issues, remote patient management using implantable cardiac devices has been performed [3]. In telemonitoring, implantable cardiac devices continually record device and patient heart status and regularly transmit the information to medical facilities via the Internet. The aims of telemonitoring are to maximize outpatient visit efficiency, promptly detect situations requiring treatment, and ensure early treatment. Studies have shown that telemonitoring decreases the frequency of urgent clinic visits and reduces cost [4]-[7].

Telemonitoring delivers data, such as heart rate, arrhythmia episodes, activity patterns, intracardiac pressure, and thoracic impedance, to medical staff without needing to interact with the patient. The lack of direct interaction may be a disservice to patients who struggle with self-care [8]. The telenursing aspect of telemedicine has evolved because it allows for the provision of both medical treatment and nursing care to a wide variety of people at reduced cost [9]. Telenursing has been associated with successful treatment of patients with chronic diseases, such as heart failure and chronic obstructive pulmonary disease [10] [11].

Innovations in the field of information technology (IT) have advanced rapidly as well. Although telenursing was provided mainly via telephone and desktop personal computer (PC) in the past, novel information terminals are expected to become the predominant mode of interaction. In particular, the tablet PC is thought to be user-friendly because of its large screen and portability, especially for individuals who are not adept at using IT devices, such as women or the elderly. In this study, using tablet PCs as novel information terminals, we provided telenursing to support patients in their native environments by centering on interactive communication.

The purpose of this project was twofold. Our first aim was to develop a tablet PC-based nursing intervention program for patients requiring telemonitoring of implantable cardiac devices. The second purpose was to evaluate the efficacy of the program using a mixed-methods research approach.

\section{Research Design}

This study used a mixed-methods research approach that multifactorially clarifies phenomena by combining quantitative and qualitative data [12]. The two phases of the study are displayed in Figure 1. In phase 1, a tablet PC-based telenursing support program was developed according to the needs of patients with heart failure undergoing telemonitoring with implantable cardiac devices and based on findings of a literature search. In phase 2, an exploratory evaluation was conducted of the telenursing support program using an experimental implantation model [13]. In this experimental model, qualitative data are implanted into an experimental design. We conducted a randomized controlled trial, which served as a preliminary investigation, and interviewed the participants. These qualitative and quantitative data were combined to evaluate the program.

\section{Phase 1: Modeling}

\subsection{Methods}

In phase 1, a semi-structured interview was first performed among the patients with heart failure, who were un- 


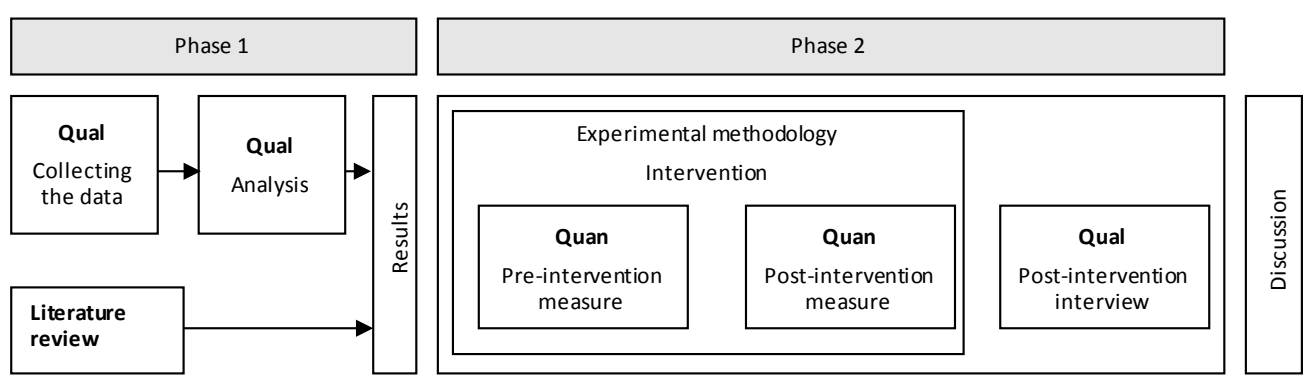

Figure 1. Research design.

dergoing telemonitoring with implantable cardiac devices, to determine their needs. Simultaneously, a literature search was performed to determine which components of heart failure disease management were effective. Finally, the components derived from the literature were combined with the subject needs to develop the telenursing support program

\subsubsection{Identifying Patient Needs}

1) Data sample and collection

The subjects were adult outpatients who had been discharged from the hospital at least 3 months prior to the study. The subjects were selected from all patients who had been identified as being high risk for rehospitalization by a physician and who underwent continuous telemonitoring with ICD, cardiac resynchronization therapy pacemaker (CRT-P), or CRT-D through the university hospitals within the metropolitan area of Japan. The study period was May 2010 to September 2010.

2) Ethical Considerations

This study (phase 1) was approved by the study ethical committee of the Saitama Medical Center Jichi University. Study candidates who provided consent after being informed of the study purposes were considered participants. We obtained a signed consent form from each participant who received the written instructions and a verbal explanation, including reassurances that participation was based on their free will and their anonymity would be secured. We thoroughly explained that refusal of further study participation or withdrawal of study participation would not influence the medical or nursing care they were provided.

3) Procedure

For participants who provided consent, a semi-structured interview was performed using an interview guide after outpatient visits. The contents of the interview consisted of thoughts about, understanding, acceptance, and expectations of telemonitoring. We used open ended questions: What do you think or feel about the telemonitoring? What are you expecting of the telemonitoring? Participants were allowed to talk freely. The contents of the interviews were recorded after we obtained each participant's consent

4) Data analysis

A thematic analysis was performed to determine patient needs for telemonitoring with implantable cardiac devices [14]. First, a verbatim record was made based on the recorded interview. After reading it repeatedly to understand the context, the minimum representation of "the needs of telemonitoring" was extracted from participant comments into a record unit. Second, the implications of each record unit were read and expressed in a single concise sentence as a code. The extracted codes were integrated for each participant, and then similar codes were integrated to extract a theme.

\subsubsection{Identifying Effective Components of Heart Failure Disease Management}

We conducted a literature search for the purpose of determining the effective components of a heart failure disease management program. Meta-analyses of heart failure published between 2005 and 2011 were searched using PubMed. The studies in which only drugs and exercise effects were evaluated were excluded. From the searched studies and guidelines, the effective components of a heart failure disease management program were extracted.

\subsubsection{Modeled Process}

The Health Belief Model [15] was used as a theoretical framework for development of the program. According 
to the Health Belief Model, the following six concepts influence activities for disease prevention and affect disease management decisions: perceived susceptibility, severity, benefits and barriers, cues to action, and selfefficacy. Patient needs (as determined from the qualitative survey) and the effective components of a heart failure disease management program (as determined from the literature search) were classified based on the six concepts of the Health Belief Model. Similar findings were integrated, from which the specific program contents were derived.

\subsection{Results}

\subsubsection{Participants}

The mean participant age was 63 years. There were more male participants (14 men; 78\%). Five participants had an ICD, and 13 participants had a CRT-D (Table 1). The average interview duration was 30 minutes.

\subsubsection{Telemonitoring Needs of the Patients with Heart Failure Using the Cardiac Device}

The following four needs of patients with heart failure undergoing telemonitoring were extracted: "check the data by myself" (patients wanted to check their own data); "reminder" (patients wanted to have something that corrected their attitude that management behavior for heart failure tends to be neglected at home); "alert" (patients said they could live a life in peace at home if when an abnormality occurred, it was reported to their physician); "advice" (patients wanted to obtain advice from medical staff rather than just send in their data). As stated earlier, to live at home safely, the patients wanted information that would help them receive medical care at home.

\subsubsection{Identifying Effective Components of Heart Failure Disease Management}

We identified three publications and three guidelines. The contents of an effective heart failure disease management program consisted of frequent contact with medical staff [16], self-monitoring [17], daily assessment, patient involvement in symptoms, mental support [18], and patient education [18]-[21].

\subsubsection{Modeled Program}

The six concepts of the Health Belief Model are shown in the lower portion of Table 2. The following four elements are related to individual cognition: Perceived severity, Perceived susceptibility, Perceived benefit, and Perceived barriers. The other two elements, Cues to action and Self-efficacy, are related to action. We created

\begin{tabular}{cc} 
Table 1. Characteristics of participants. \\
\hline Demographic variable & Interview (n = 18) \\
\hline \multicolumn{2}{c}{ Demographic characteristics } \\
Gender (male) & $14(78 \%)$ \\
Age (years) & $63.22 \pm 9.04$ \\
Living situation (living alone) & 0 \\
Employment (employed) & $3(16 \%)$ \\
Cardiac characteristics & \\
Etiology of heart failure & \\
Dilated cardiomyopathy & $6(33 \%)$ \\
Ischemic heart disease & $6(33 \%)$ \\
Valvular disease & $4(22 \%)$ \\
Others & $2(11 \%)$ \\
NYHA functional class & $18(100 \%)$ \\
II & \\
Device & $5(28 \%)$ \\
ICD & $13(72 \%)$ \\
CRT-D &
\end{tabular}


Table 2. Modeled program.

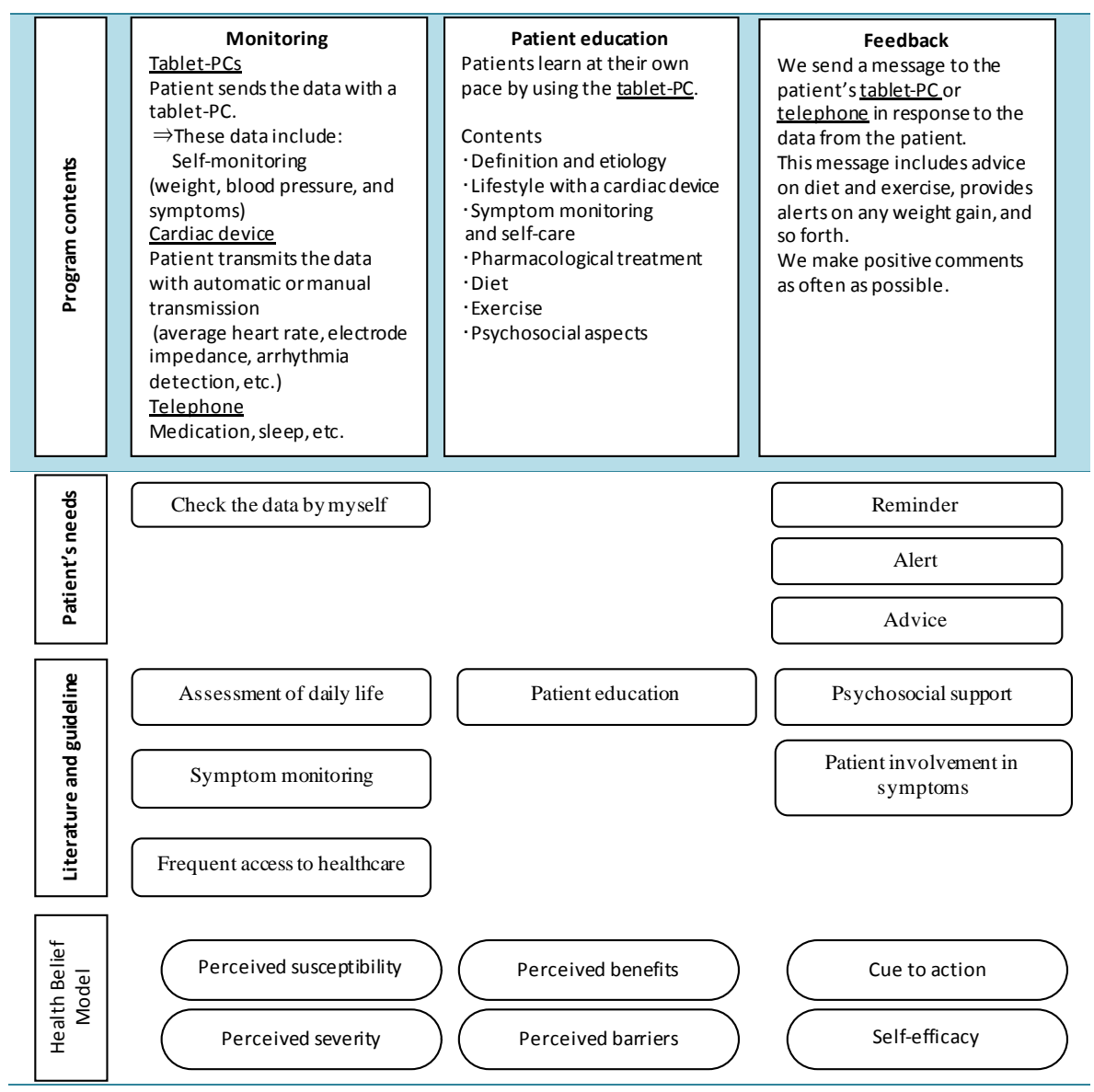

the program to enable action by encouraging the desired cognition.

The needs of patients undergoing telemonitoring with implantable cardiac devices and the results of the literature search were classified accordingly. The contents of the program that satisfied these results are shown in the upper portion of Table 2.

To produce the desired cognition, people need to recognize the present condition and acquire the proper knowledge in the health belief model. If patients take interest in their data, they will better understand themselves and their condition. It is recommended that a health professional follow a patient to ensure the patient's actions are in compliance with the literature and guideline. Therefore, one of the components of the program is monitoring. In addition, we included patient education in the program so that patients might acquire knowledge appropriate to their condition.

When patients perform a health-related action, that action must be preceded by a cause in order to raise selfefficacy in the health belief model. The following keywords indicate patients want a cue to action: Reminder, Alert, and Advice. Good feedback is more than just a reply; it gives the suitable cue to action for a patient's present condition or raises self-efficacy. Mental support by a health professional bolsters the patient's efforts.

The program had three components. The first component was monitoring, which was performed using a tablet PC, implantable cardiac device, and telephone. The participants used a tablet PC to send their body weight, blood pressure, and symptoms to the medical team from home. When the participants sent their data to the medical staff, they performed self-monitoring at the same time. A nurse confirmed the implantable cardiac device data (e.g., mean heart rate, impedance, and arrhythmia) via telemonitoring and called each patient once monthly to assess medication adherence, sleep, and mental status. The second component was patient education. Participants were asked to participate in e-learning to learn the basics of heart failure and implantable cardiac devices, and to learn about preventing heart failure. The educational contents were prepared using the Heart Failure Society of America education module [22] and the chronic heart failure treatment guideline [19]. To increase the 
attendance rate, the content was limited to 3 minutes per module. The third component was feedback of data to the participants. Nurses informed participants of their data as clearly and positively as possible twice a week. Participants were educated mainly on diet or fluid restriction as needed. The nurses used a tablet PC and telephone to communicate with the participants.

\subsubsection{Study Program}

Cooperation between the patient, hospital, and university, as well as relationships between the telemonitoring system and the tablet PC-based telenursing support are shown on the left side of Figure 2. The online self-care website used in the study is shown on the right side of Figure 2. The website design was instinctive and inspired by an automated teller machine (ATM).

\section{Phase 2: Preliminary Investigation}

\subsection{Methods}

A mixed-methods study was performed to evaluate the effects of the program developed in phase 1. Participants were interviewed about their experience in order to acquire qualitative data.

\subsubsection{Data Sample and Collection}

A general hospital located in the medical service area in Japan was selected as the study site because it was in a medically underserved area, where the population would especially benefit from telenursing. The participants met all of the following criteria: adult outpatients undergoing continuous telemonitoring with ICD, CRT-P, or CRT-D; hospitalization due to worsening heart failure in the past year or a left ventricular ejection fraction $\leq$ $40 \%$; and able to input data using a tablet PC (or the presence of a family member, who could perform the data entry). Participants in phase 2 were not included in phase 1. The 6-month study period (March 2012 to October 2013) included a 3-month intervention period and a 3-month follow-up period. Participants in the usual care (control) group were followed up on an outpatient basis by a cardiovascular specialist every 1 - 3 months.

\subsubsection{Ethical Considerations}

Phase 2 of this study was approved by the study ethical committee of the Kameda Medical Center. The procedure for obtaining informed consent was the same as in phase 1.

\subsubsection{Randomization}

We conducted a randomized trial. The participants were randomly assigned to the intervention and usual care groups and each provided informed consent [23] [24]. This method was adopted because it simplifies the process for obtaining consent for new treatments [25], and the bias that might result from patient preference could be excluded [26]. Informed consent was obtained from the participants in both groups after randomization [24]. A minimization method was used for the assignment [27]. The assignment factors of the qualified participants were age at inclusion in this study ( $\leq 64$ years old or $\geq 65$ years old), sex, and device type (ICD or CRT-D).

\subsubsection{Measurements and Variables}

The outcome measures were as follows: rehospitalization rate, urgent clinic visits rate, quality of life (QOL), self-efficacy, and self-care behavior for heart failure. For QOL, the SF-8 Health Survey (standard Japanese version) [28] was used. A higher score indicated better QOL. For self-efficacy, health behavior-related self-efficacy for the chronic disease patient [29] was used. A lower score indicated better self-care. For self-care behavior for heart failure, the Japanese version of the European Heart Failure Self-Care Behavior Scale [30] [31] was used. A higher score indicated better self-care.

\subsubsection{Statistical Analysis}

An intention-to-treat analysis was performed. Fisher's exact test was used to compare the attributes between groups at program initiation. For ordinal scales, once the distribution of data was assessed using the Shapiro-Wilk test, either a two-sample $t$ test or a Mann-Whitney test was applied according to the presence or absence of normality. To determine readmission and urgent clinic visit rates, the time period between study initiation and event occurrence was used as the target variable, while a survival analysis was performed using Kaplan-Meier 


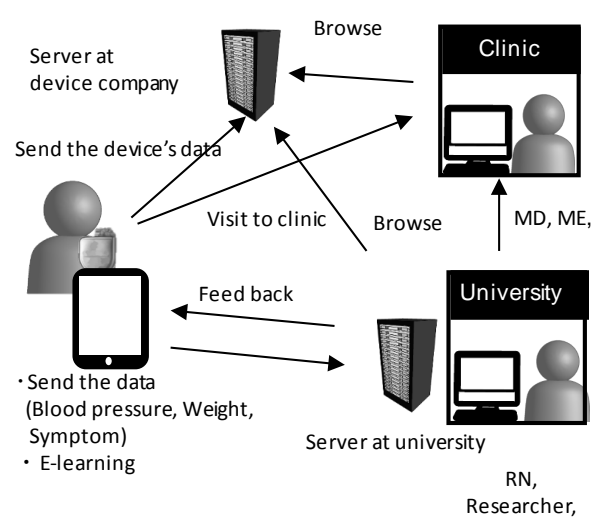

(1)

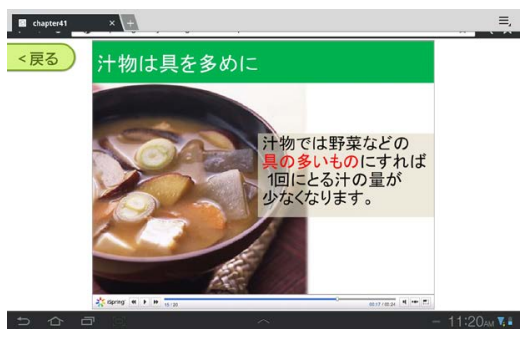

(3)

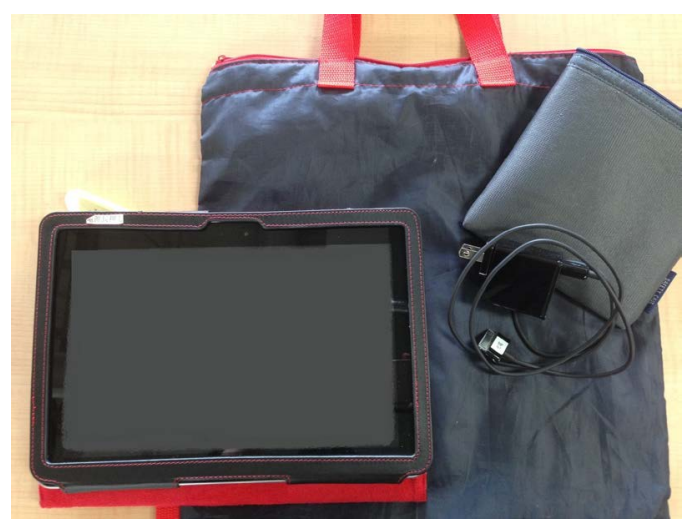

(2)

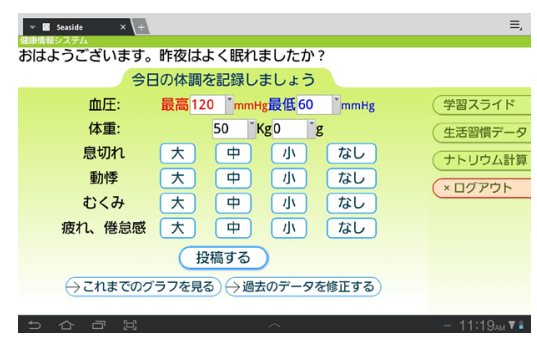

(4)
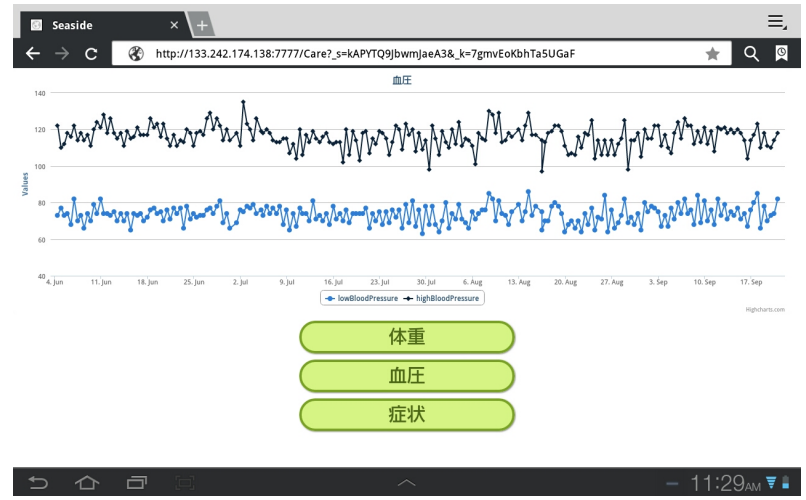

(5)

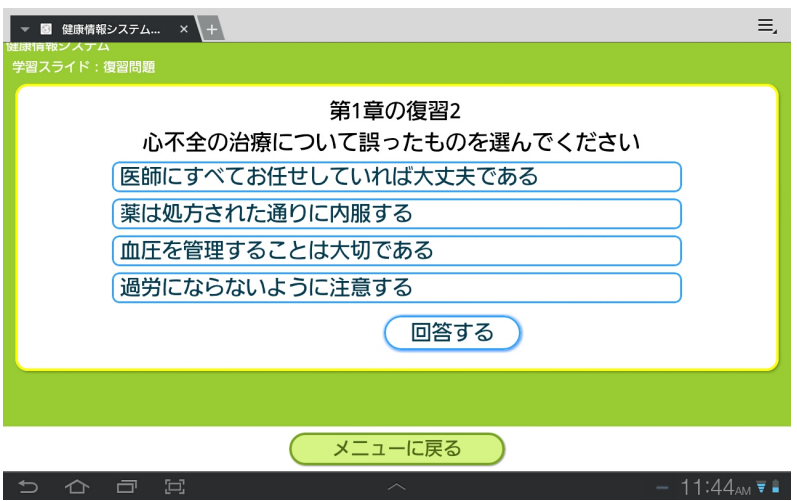

(6)

Figure 2. Overview of the nursing intervention system and online self-care website. (1) Diagrammatic representation of the telemonitoring system used in the trial, (2) Tablet-PC set and E-learning, (3) Main page of online self-care website where participants send information about blood pressure, weight, and symptoms (e.g., breath shortness, palpitation, edema, and fatigue), (4) Review test, and (5) Blood pressure chart. 
survival analysis according to the two groups. To analyze changes in each scale score, the Wilcoxon signed-rank test was used for intragroup comparisons, and the Wilcoxon rank sum test was used for intergroup comparisons. The SAS 9.2 statistical software (SAS Institute Inc., NC, USA) was used, and the significance level was set at 0.05 .

\subsubsection{Qualitative Data Regarding Patient Experiences}

To study patient experiences during the program, data were collected by semi-structured interview following the intervention, and a thematic analysis [14] was performed. First, a verbatim record was made based on the recorded interview. Second, after repeated readings for familiarization with data, the representations associated with patient experiences of the telenursing support program were extracted. Third, we generated initial codes to describe the data extracted. Fourth, the codes were integrated for each participant, and then similar codes were integrated to search for a theme. Fifth, themes were reviewed, defined, and named. To ensure reliability, we made repeated checks, examinations, and corrections to ensure that each code and theme was suitably named by researchers.

\subsection{Results}

\subsubsection{Participants}

Forty patients met the study inclusion criteria: 23 and 17 were assigned to the intervention and control groups, respectively. Of the 23 patients who were assigned to the intervention group, 17 provided consent and six refused to participate in the study. The reasons for refusal were: "the current treatment is sufficient for me"; "I am too old to operate a personal computer"; "it seems to be troublesome"; and two patients stated "I am busy because of my work." Three patients in the intervention group dropped out of the study for the following reasons: "I am busy," and "I suffered a great psychological shock due to the sudden death of a relative." Of the 17 patients assigned to the control group, 16 provided consent, 1 refused to participate in the study for lack of interest, and another participant did not complete the questionnaire and was therefore excluded (Figure 3).

\subsubsection{Baseline Characteristics}

Forty patients met the study inclusion criteria: 23 and 17 were assigned to the intervention and control groups, respectively. Of the 23 patients who were assigned to the intervention group, 17 provided consent and six refused to participate in the study. The reasons for refusal were: "the current treatment is sufficient for me"; "I am too old to operate a personal computer"; "it seems to be troublesome"; and two patients stated "I am busy because of my work." Three patients in the intervention group dropped out of the study for the following reasons: "I am busy," and "I suffered a great psychological shock due to the sudden death of a relative." Of the 17 patients assigned to the control group, 16 provided consent, 1 refused to participate in the study for lack of interest, and another participant did not complete the questionnaire and was therefore excluded (Table 3).

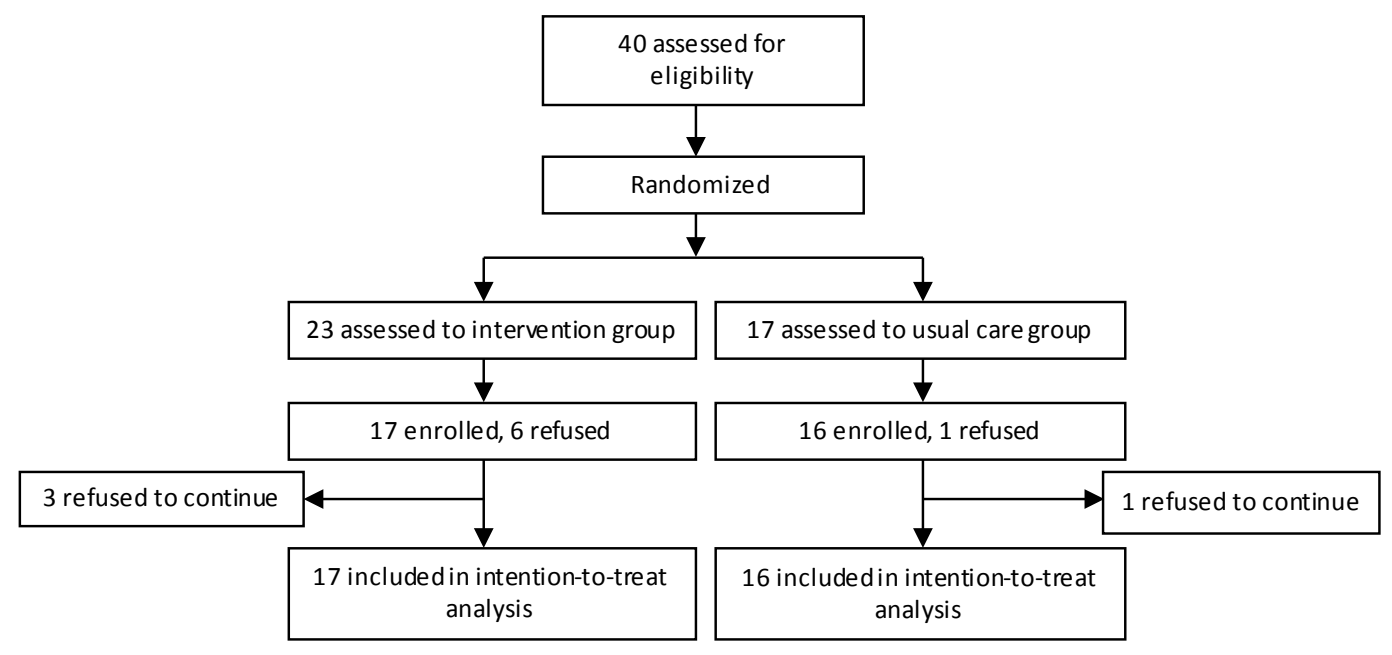

Figure 3. Flow of participants throughout this study. 
Table 3. Baseline characteristics.

\begin{tabular}{|c|c|c|c|}
\hline Demographic variable & Intervention $(\mathrm{n}=17)$ & Usual care $(\mathrm{n}=16)$ & $\mathrm{p}$ \\
\hline Gender (male) & $13(76 \%)$ & $12(75 \%)$ & 1.0000 \\
\hline Age (years \pm SD) & $61.94 \pm 12.19$ & $64.12 \pm 9.27$ & 0.9857 \\
\hline Living situation (living alone) & $2(11 \%)$ & $2(12 \%)$ & 0.6880 \\
\hline Employment (employed) & $5(29 \%)$ & $3(19 \%)$ & 1.0000 \\
\hline Body weight (kilograms) & $66.6 \pm 16.98$ & $61.67 \pm 10.35$ & 0.7098 \\
\hline \multicolumn{4}{|l|}{ Cardiac characteristics } \\
\hline \multicolumn{4}{|l|}{ Etiology of heart failure } \\
\hline Dilated cardiomyopathy & $6(36 \%)$ & $5(32 \%)$ & 1.0000 \\
\hline Ischemic heart disease & $5(29 \%)$ & $7(44 \%)$ & 0.4813 \\
\hline Valvular disease & $1(6 \%)$ & 0 & 1.0000 \\
\hline Hypertrophic cardiomyopathy & 0 & $2(12 \%)$ & 0.2273 \\
\hline Others & $5(29 \%)$ & $2(12 \%)$ & 0.3983 \\
\hline \multicolumn{4}{|l|}{ NYHA functional class } \\
\hline I & $5(29 \%)$ & $5(31 \%)$ & 1.0000 \\
\hline II & $10(59 \%)$ & $9(56 \%)$ & 1.0000 \\
\hline III & $2(11 \%)$ & $2(13 \%)$ & 1.0000 \\
\hline LVEF & $42.97 \pm 11.48$ & $41.91 \pm 9.61$ & 0.8996 \\
\hline BNP & $204.90 \pm 196.45$ & $344.59 \pm 384.86$ & 0.3440 \\
\hline \multicolumn{4}{|l|}{ Treatment } \\
\hline \multicolumn{4}{|l|}{ Medication } \\
\hline Beta blocker & 16 (94\%) & 14 (88\%) & 1.0000 \\
\hline ACE/ARB & $8(48 \%)$ & $6(38 \%)$ & 0.7283 \\
\hline Diuretics & 11 (65\%) & 10 (63\%) & 1.0000 \\
\hline \multicolumn{4}{|l|}{ Device } \\
\hline ICD & 11 (64\%) & $10(62 \%)$ & 1.0000 \\
\hline CRT-D & $6(36 \%)$ & $6(38 \%)$ & 1.0000 \\
\hline
\end{tabular}

\subsubsection{Unplanned Hospitalizations and Emergency Room Visits}

The rates of urgent hospital admissions associated with the heart within 6 months after study initiation were 11\% and $18 \%$ in the intervention and control groups, respectively. The rate difference was not statistically significant based on two different tests: the log rank test $(\mathrm{p}=0.3017)$ and the Cox regression analysis using the intervention group as a reference (hazard ratio [HR] 0.82; 95\% confidence interval [CI] $0.42-12.42$; $\mathrm{p}=0.3441$ ). Within 6 months after study initiation, the unplanned consultation rates associated with the heart were $11 \%$ and $18 \%$ in the intervention and control groups, respectively. This rate difference also was not statistically significant based on the two tests: $\log$ rank test $(\mathrm{p}=0.3179)$ and Cox regression analysis using the intervention group as a reference (HR 0.45; 95\% CI, 0.26 - 9.52; p = 0.6172) (Figure 4).

\subsubsection{QOL, Heart Failure Self-Care, and Self-Efficacy}

The amount of change in each score based on the intervention time point was calculated and an intragroup comparison was performed. As shown in Table 4, the degrees of change were compared between the groups, but no significant differences were found.

\subsubsection{Qualitative Data Regarding Patient Experiences}

Fourteen participants in the intervention group, who completed the study, were interviewed just after the end of the program. The interview was performed for an average of 40 minutes. Table 5 shows that three categories were ultimately derived. 


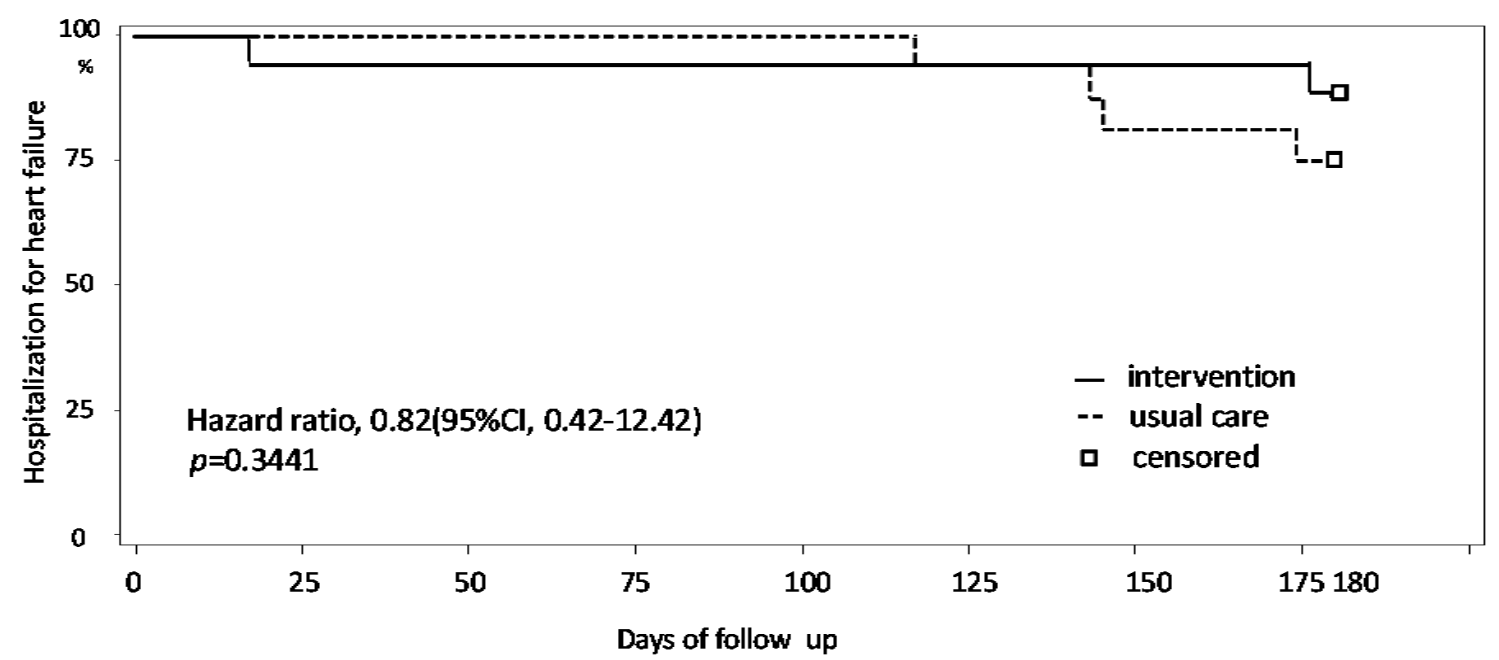

No.at Risk

\begin{tabular}{|c|c|c|c|c|c|c|c|}
\hline Intervention 17 & 16 & 16 & 16 & 16 & 16 & 16 & $16 \quad 15$ \\
\hline Usual care 16 & 16 & 16 & 16 & 16 & 15 & 13 & 12 \\
\hline
\end{tabular}

(a)

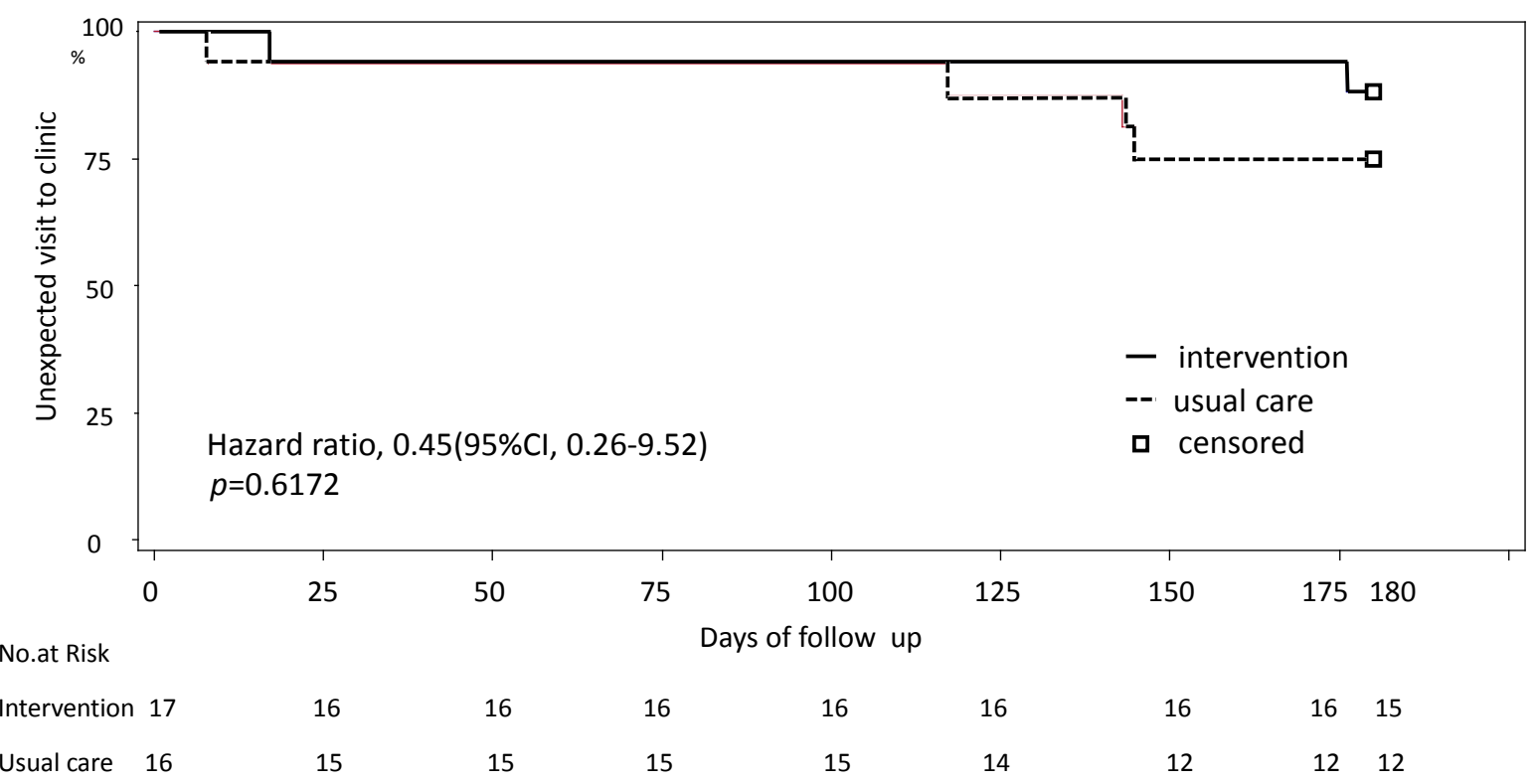

(b)

Figure 4. Kaplan-Meier curve depicting the probability of survival ((a) Hospitalization for heart failure, (b) Unexpected visit to clinic) between the 2 groups (experimental is a solid line and the control is a dotted line), censored at 180 days.

1) Getting a sense of safety

Most participants reported developing a sense of safety through participation in the program. The participants who experienced multiple hospitalizations led a life of anxiety that may worsen. However, they felt safe, like being followed by an escort runner during program participation. The sense of security was strengthened by knowing that no abnormality would go undetected.

"In this program, I felt relieved when I received a message such as no arrhythmia was detected. I felt assured for 3 months of the study period. Even if the message indicated that a slight arrhythmia was found, I felt that my condition was understood. If something occurs or if I contact you, I can receive some reply or advice. In such aspects, I was very relieved.” 
Table 4. Within-group comparison and between-group comparison.

\begin{tabular}{|c|c|c|c|c|c|}
\hline & \multicolumn{2}{|c|}{$\begin{array}{l}\text { Intervention group } \\
\quad(\mathrm{n}=14)\end{array}$} & \multicolumn{2}{|c|}{$\begin{array}{l}\text { Usual care group } \\
\quad(\mathrm{n}=15)\end{array}$} & \multirow{2}{*}{$\begin{array}{l}\text { Intergroup } \\
\text { p value }\end{array}$} \\
\hline & $\begin{array}{c}\text { Change } \\
\text { (3mo-baseline) }\end{array}$ & $\begin{array}{l}\text { Within-group } \\
\text { p value }\end{array}$ & $\begin{array}{c}\text { Change } \\
\text { (3mo-baseline) }\end{array}$ & $\begin{array}{l}\text { Within-group } \\
\text { p value }\end{array}$ & \\
\hline SF8: Physical $^{\mathrm{a}}$ & $-2.24 \pm 9.76$ & 0.5416 & $2.47 \pm 5.24$ & 0.1514 & 0.1761 \\
\hline SF8: Mental ${ }^{\mathrm{a}}$ & $-1.56 \pm 9.65$ & 0.7148 & $-2.38 \pm 6.51$ & 0.3028 & 0.4321 \\
\hline EHF ScB scale ${ }^{\mathrm{b}}$ & $-3.00 \pm 6.30$ & 0.0833 & $-1.33 \pm 6.34$ & 0.5513 & 0.3141 \\
\hline Self-efficacy on health behavior ${ }^{c}$ & $-2.15 \pm 11.18$ & 0.6914 & $0.85 \pm 6.79$ & 0.9224 & 0.8369 \\
\hline
\end{tabular}

Abbreviations: SF8, SF-8 ${ }^{\mathrm{TM}}$ Health Survey; HADS, Hospital Anxiety and Depression Scale; EHF ScB scale, European Heart Failure Self-Care Behavior Scale; ${ }^{a}$ Higher score means better QOL; ${ }^{b}$ Lower score means better self-care; ${ }^{\mathrm{C}}$ Higher score means better self-efficacy.

\begin{tabular}{|c|c|}
\hline Theme & code \\
\hline Getting a sense of safety & $\begin{array}{l}\cdot \text { Someone is watching over me } \\
\cdot \text { Having an escort }\end{array}$ \\
\hline Triggering a health behavior change & $\begin{array}{l}\text { - Increased health awareness } \\
\text { - Got a supportive push } \\
\text { - Received a warning }\end{array}$ \\
\hline Feeling like burden & $\begin{array}{l}\cdot \text { Bothersome to send data } \\
\text { - Trouble using a tablet-PC }\end{array}$ \\
\hline
\end{tabular}

2) Triggering a health behavior change

Most of the participants were encouraged to change their health behaviors by participating in this program. Even if they felt some abnormalities, they lived in a place that was too far from a medical institution and tended to hesitate before contacting a hospital. However, they became sensitive to changes in their symptoms because their level of awareness was increased during their participation in the program. Their consultation behaviors were also promoted since they communicated regularly with the nurses.

"I was not motivated to call you only when I felt considerably abnormal, but since I called you every day, I think that I am now more likely to call you if I feel an unusual condition.”

When an abnormality in participant data was found, the attending nurse called the participant, who considered this call a warning and improved their behavior.

"My body weight increased to around $108 \mathrm{~kg}$ and I received a call. After that point, I watched my weight more carefully, and it returned to $104 \mathrm{~kg}$."

3) Feeling like a burden

Some participants felt that participating in the program was a burden. Although the tablet PC was easy to use, they felt that sending messages daily was cumbersome. They also felt burdened by occasional problems that occurred with the tablet PC.

"I don't have many things to do at home, but it is slightly troublesome that I have to send a message every day. As such, I decided to send a message once every 3 days.”

\section{Discussion}

In this study, a tablet PC program was developed, and its efficacy was examined through interviews and a review of the literature regarding the needs of patients undergoing telemonitoring with implantable cardiac devices. We hypothesized that program implementation might result in: early detection of abnormalities and mental support; reduced rates of readmissions and urgent clinic visits; and improved QOL or heart failure behaviors. However, our statistical data did not support these hypotheses. There seemed to be several causes for this. First, the program period might have been too short. The quantitative survey showed no positive results, while the qualitative survey indicated signs of behavioral changes in participants. For instance, participants who thought that measuring blood pressure and body weight was necessary, but did not measure them, developed healthy beha- 
viors. Since behavioral change usually takes 3 months, we set the program period to 3 months. However, the lack of impact might be reflected by the end point because the program ended when behavioral changes started to happen.

Second, the results might have been influenced by the small sample size. QOL in particular did not improve, which seemed to be due to one of the following reasons: 1) patients in the intervention group had low QOL scores at study initiation; 2) events not associated with the heart occurred in several participants (e.g., cancer occurred or a family member's health condition worsened). These possible causes might have influenced the overall results.

Most participants in this study were unfamiliar with IT; however, the continuance rate of the program exceeded $80 \%$. Although participants used an unfamiliar information terminal, the continuance rate was high. A previous, representative, large-scale study investigated the efficacy of telemonitoring using a push-button telephone and automated voice for patients with heart failure [32]. Only 55\% of the participants finished that study.

The difference in the continuance rate between that study and the present study seems to be attributable to differences in feedback. The provision of specific feedback in contrast to an automated response seemed to increase participants' interest, which might have increased their motivation to continue the program.

In this study, we primarily communicated with the participants using a tablet PC. However, limited information was obtained, so face-to-face interactions might also be necessary. Many of these participants had no easy access to a hospital owing to distance or traffic conditions. Therefore, use of not only the current intervention but also video technology such as Skype to view the participant's face may be effective.

Next, we examined the outcome measures, including unplanned consultations. However, one case in which unplanned consultation was used as the end point seemed to include trouble. In this case, in which a participant hesitated about whether a consultation was required for the present symptom, the intervention prompted the patient to act, thereby receiving an appropriate and timely consultation. It is preferable to avoid unplanned consultations whenever possible. If early consultation can prevent aggravation of symptoms, participants will benefit. In some earlier studies [33]-[35], unplanned consultation was defined as one of the intervention outcome measures. Here, it seemed necessary to evaluate the intervention from different angles using multiple end points.

Although a positive result was not obtained, we cannot deny the validity of the entire program. The tablet PC, which has become widespread, is easy to operate and can be used by the elderly as well. Considering that this program showed a higher continuance rate, the aforementioned issues were improved and reexamined, which should contribute to future use in clinical practice. While society continues to age rapidly, the number of people who are cared for at home has increased. Therefore, in an institution with a wide medical service area such as that in this study, it will be necessary to examine the effects of the program with cooperation of home-visit nursing stations in the future.

\section{Limitations}

This study has some limitations. First, it had a small sample size, and a single institution, which was made clear in the results. Since patients with implantable cardiac devices did not increase in number as anticipated, the sample size estimated at the planning stage was not reached. Therefore, the statistical analysis has limitations. Second, elderly healthcare dependents were not discussed. There are many elderly people among heart failure patients so the implementation of a program through a caregiver or a visiting nurse must be considered. Third, the cost of the intervention program was not discussed. Cost is an important factor that deserves mention because medical costs are subject to restrictions. Cost should be examined further in future research.

\section{Competing Interests}

The authors declare that they have no competing interests.

\section{Acknowledgements}

We thank the patients who took the time to participate in this research, as well as the clinical staff of the participating institutions. We are also indebted to Dr. Suzuki and Ms. Iizuka for their support in solving any administrative problems.

The Pfizer Health Research Foundation and Okawa Foundation provided financial support for this study. 


\section{References}

[1] Okura, Y., Ramadan, M.M., Ohno, Y., Mitsuma, W., Tanaka, K., Ito, M., Suzuki, K., Tanabe, N., Kodama, M. and Aizawa, Y. (2008) Impending Epidemic: Future Projection of Heart Failure in Japan to the Year 2055. Circulation Journal, 72, 489-491. http://dx.doi.org/10.1253/circj.72.489

[2] Jeon, Y.H., Kraus, S.G., Jowsey, T. and Glasgow, N.J. (2010) The Experience of Living with Chronic Heart Failure: A Narrative Review of Qualitative Studies. BMC Health Services Research, 10, 77. http://dx.doi.org/10.1186/1472-6963-10-77

[3] Movsowitz, C. and Mittal, S. (2011) Remote Patient Management Using Implantable Devices. Journal of Interventional Cardiac Electrophysiology, 31, 81-90. http://dx.doi.org/10.1007/s10840-011-9548-2

[4] Oliveira, M., Silva Cunha, P. and da Silva, N. (2013) Remote Monitoring for Follow-Up of Patients with Implantable Cardiac Devices. Revista Portuguesa de Cardiologia, 32, 185-190. http://dx.doi.org/10.1016/j.repc.2012.08.006

[5] Klersy, C., De Silvestri, A., Gabutti, G., Regoli, F. and Auricchio, A. (2009) A Meta-Analysis of Remote Monitoring of Heart Failure Patients. Journal of the American College of Cardiology, 54, 1683-1694. http://dx.doi.org/10.1016/j.jacc.2009.08.017

[6] Marzegalli, M., Landolina, M., Lunati, M., Perego, G.B., Pappone, A., Guenzati, G., Campana, C., Frigerio, M., Parati, G., Curnis, A., Colangelo, I. and Valsecchi, S. (2009) Design of the Evolution of Management Strategies of Heart Failure Patients with Implantable Defibrillators (EVOLVO) Study to Assess the Ability of Remote Monitoring to Treat and Triage Patients More Effectively. Trials, 10, 42. http://dx.doi.org/10.1186/1745-6215-10-42

[7] Boveda, S., Marijon, E., Jacob, S., Defaye, P., Winter, J.B., Bulava, A., Gras, D., Albenque, J.P., Combes, N., Pavin, D., Delarche, N., Teubl, A., Lambiez, M., Chevalier, P. and Mona Lisa Study Group (2009) Incidence and Prognostic Significance of Sustained Ventricular Tachycardias in Heart Failure Patients Implanted with Biventricular Pacemakers without a Back-Up Defibrillator: Results from the Prospective, Multicentre, Mona Lisa Cohort Study. European Heart Journal, 30, 1237-1244. http://dx.doi.org/10.1093/eurheartj/ehp071

[8] Umeda, A. and Inoue, T. (2012) Descriptive Study of the Life with Remote Monitoring of Heart Devices. Journal of the Ochanomizu Association for Academic Nursing, 7, 30-41.

[9] Kumar, S. and Snocks, H. (2011) Telenursing (Health Informatics). Springer, London. http://dx.doi.org/10.1007/978-0-85729-529-3

[10] Clark, R.A., Inglis, S.C., McAlister, F.A., Cleland, J.G. and Stewart, S. (2007) Telemonitoring or Structured Telephone Support Programmes for Patients with Chronic Heart Failure: Systematic Review and Meta-Analysis. BMJ, $334,942$. http://dx.doi.org/10.1136/bmj.39156.536968.55

[11] Kamei, T., Yamamoto, Y., Kajii, F., Nakayama, Y. and Kawakami, C. (2013) Systematic Review and Meta-Analysis of Studies Involving Telehome Monitoring-Based Telenursing for Patients with Chronic Obstructive Pulmonary Disease. Japan Journal of Nursing Science, 10, 180-192. http://dx.doi.org/10.1111/j.1742-7924.2012.00228.x

[12] Polit, D.B. (2011) CT: Nursing Research, North American Edition. Generating and Assessing Evidence for Nursing Practice. 9th Edition, Lippincott Williams \& Wilkins, Philadelphia.

[13] Creswell, J.W. and Plano Clark, V.L. (2010) Designing and Conducting Mixed Methods Research. 2nd Edition, SAGE Publications, Inc., Washington DC.

[14] Braun, V. and Clarke, V. (2006) Using Thematic Analysis in Psychology. Qualitative Research in Psychology, 3, 77101. http://dx.doi.org/10.1191/1478088706qp063oa

[15] Rosenstock, I.M., Strecher, V.J. and Becker, M.H. (1988) Social Learning Theory and the Health Belief Model. Health Education Quarterly, 15, 175-183. http://dx.doi.org/10.1177/109019818801500203

[16] Whellan, D.J., Hasselblad, V., Peterson, E., O’Connor, C.M. and Schulman, K.A. (2005) Meta-Analysis and Review of Heart Failure Disease Management Randomized Controlled Clinical Trials. American Heart Journal, 149, 722-729. http://dx.doi.org/10.1016/j.ahj.2004.09.023

[17] Eastwood, C.A., Travis, L., Morgenstern, T.T. and Donaho, E.K. (2007) Weight and Symptom Diary for Self-Monitoring in Heart Failure Clinic Patients. Journal of Cardiovascular Nursing, 22, 382-389. http://dx.doi.org/10.1097/01.JCN.0000287027.49628.a7

[18] Hunt, S.A., Abraham, W.T., Chin, M.H., Feldman, A.M., Francis, G.S., Ganiats, T.G., Jessup, M., Konstam, M.A., Mancini, D.M., Michl, K., Oates, J.A., Rahko, P.S., Silver, M.A., Stevenson, L.W., Yancy, C.W. and American College of Cardiology Foundation; American Heart Association (2009) 2009 Focused Update Incorporated into the ACC/AHA 2005 Guidelines for the Diagnosis and Management of Heart Failure in Adults A Report of the American College of Cardiology Foundation/American Heart Association Task Force on Practice Guidelines Developed in Collaboration with the International Society for Heart and Lung Transplantation. Journal of the American College of Cardiology, 53, e1-e90. http://dx.doi.org/10.1016/j.jacc.2008.11.013 
[19] The Japanese Circulation Joint Working Group (2011) Guidelines for Treatment of Chronic Heart Failure (JCS 2010). http://www.j-circ.or.jp/guideline/pdf/JCS2010_matsuzaki_d.pdf

[20] McMurray, J.J., Adamopoulos, S., Anker, S.D., Auricchio, A., Böhm, M., Dickstein, K., Falk, V., Filippatos, G., Fonseca, C., Gomez-Sanchez, M.A., Jaarsma, T., Køber, L., Lip, G.Y., Maggioni, A.P., Parkhomenko, A., Pieske, B.M., Popescu, B.A., Rønnevik, P.K., Rutten, F.H., Schwitter, J., Seferovic, P., Stepinska, J., Trindade, P.T., Voors, A.A., Zannad, F., Zeiher, A. and ESC Committee for Practice Guidelines (2012) ESC Guidelines for the Diagnosis and Treatment of Acute and Chronic Heart Failure 2012: The Task Force for the Diagnosis and Treatment of Acute and Chronic Heart Failure 2012 of the European Society of Cardiology. Developed in Collaboration with the Heart Failure Association (HFA) of the ESC. European Heart Journal, 33, 1787-1847. http://dx.doi.org/10.1093/eurheartj/ehs104

[21] Savard, L.A., Thompson, D.R. and Clark, A.M. (2011) A Meta-Review of Evidence on Heart Failure Disease Management Programs: The Challenges of Describing and Synthesizing Evidence on Complex Interventions. Trials, 12, 194. http://dx.doi.org/10.1186/1745-6215-12-194

[22] Heart Failure Society of America (2006) Educational Modules on Heart Failure. http://www.hfsa.org/ heart_failure_education_modules.asp

[23] Zelen, M. (1979) A New Design for Randomized Clinical Trials. New England Journal of Medicine, 300, $1242-1245$. http://dx.doi.org/10.1056/NEJM197905313002203

[24] Adamson, J., Cockayne, S., Puffer, S. and Torgerson, D.J. (2006) Review of Randomised Trials Using the Post-Randomised Consent (Zelen’s) Design. Contemporary Clinical Trials, 27, 305-319. http://dx.doi.org/10.1016/j.cct.2005.11.003

[25] Snowden, J.A., Biggs, J.C., Milliken, S.T., Fuller, A., Staniforth, D., Passuello, F., Renwick, J. and Brooks, P.M. (1998) A Randomised, Blinded, Placebo-Controlled, Dose Escalation Study of the Tolerability and Efficacy of Filgrastim for Haemopoietic Stem Cell Mobilisation in Patients with Severe Active Rheumatoid Arthritis. Bone Marrow Transplantation, 22, 1035-1041. http://dx.doi.org/10.1038/sj.bmt.1701486

[26] Torgerson, D. and Torgerson, C. (2010) Designing Randomised Trials in Health, Education and the Social Sciences: An Introduction. Japanese Version, Nippon Hyoron Sha, Tokyo.

[27] Pocock, S.J. (1979) Allocation of Patients to Treatment in Clinical Trials. Biometrics, 35, 183-197. http://dx.doi.org/10.2307/2529944

[28] Fukuhara, S. and Suzukamo, Y. (2005) Health-Related Quality of Life-SF8 and SF36. Journal of Clinical and Experimental Medicine, 213, 133-136.

[29] Kim, W., Shimada, H. and Sakano, Y. (1996) The Relationship between Self-Efficacy on Health Behavior and Stress Responses in Chronic Disease Patients. Japanese Journal of Psychosomatic Medicine, 36, 499-505.

[30] Jaarsma, T., Strömberg, A., Mårtensson, J. and Dracup, K. (2003) Development and Testing of the European Heart Failure Self-Care Behaviour Scale. European Journal of Heart Failure, 5, 363-370. http://dx.doi.org/10.1016/S1388-9842(02)00253-2

[31] Kato, N., Ito, N., Kinugawa, K. and Kazuma, K. (2008) Validity and Reliability of the Japanese Version of the European Heart Failure Self-Care Behavior Scale. European Journal of Cardiovascular Nursing, 7, 284-289. http://dx.doi.org/10.1016/j.ejcnurse.2007.12.005

[32] Chaudhry, S.I., Mattera, J.A., Curtis, J.P., Spertus, J.A., Herrin, J., Lin, Z., Phillips, C.O., Hodshon, B.V., Cooper, L.S. and Krumholz, H.M. (2010) Telemonitoring in Patients with Heart Failure. New England Journal of Medicine, 363, 2301-2309. http://dx.doi.org/10.1056/NEJMoa1010029

[33] Seibert, P.S., Whitmore, T.A., Patterson, C., Parker, P.D., Otto, C., Basom, J., Whitener, N. and Zimmerman, C.G. (2008) Telemedicine Facilitates CHF Home Health Care for Those with Systolic Dysfunction. International Journal of Telemedicine and Applications, 2008, Article ID: 235031. http://dx.doi.org/10.1155/2008/235031

[34] Bocchi, E.A., Cruz, F., Guimarães, G., Pinho Moreira, L.F., Issa, V.S., Ayub Ferreira, S.M., Chizzola, P.R., Souza, G.E., Brandão, S. and Bacal, F. (2008) Long-Term Prospective, Randomized, Controlled Study Using Repetitive Education at Six-Month Intervals and Monitoring for Adherence in Heart Failure Outpatients: The REMADHE Trial. Circulation: Heart Failure, 1, 115-124. http://dx.doi.org/10.1161/CIRCHEARTFAILURE.107.744870

[35] Ramachandran, K., Husain, N., Maikhuri, R., Seth, S., Vij, A., Kumar, M., Srivastava, N., Prabhakaran, D., Airan, B. and Reddy, KS. (2007) Impact of a Comprehensive Telephone-Based Disease Management Programme on Qualityof-Life in Patients with Heart Failure. National Medical Journal of India, 20, 67-73. 